\title{
The Effect of Vitamin $B_{12}$ and Biotin on the Metabolism of Vitamin $B_{12}$ in Biotin-Deficient Rats
}

\author{
By P. PUDDU AND M. MARCHETTI \\ Istituto Chimica Biologica dell'Università di Bologna, Bologna, Italy
}

(Received 12 October 1964)

\begin{abstract}
1. The effect of the administration of vitamin $B_{12}$ and biotin on the metabolic pattern of vitamin $B_{12}$ in biotin-deficient rats was studied. 2. No significant changes in the absorption and excretion of orally administered [ $\left.{ }^{58} \mathrm{Co}\right]$ vitamin $\mathrm{B}_{12}$ were noted either in vitamin $B_{12}$-treated and or in biotin-fed rats. A significant decrease of the uptake of orally given [ ${ }^{58} \mathrm{Co}$ ] vitamin $\mathrm{B}_{12}$ was observed in the liver and kidneys of biotin-treated rats, whereas an increase of uptake in the kidneys of vitamin $\mathrm{B}_{12}$-treated rats was noted as compared with biotin-deficient animals. 3. No significant difference in the excretion of radioactivity was noted between biotin deficient and biotin-fed rats when [ $\left.{ }^{58} \mathrm{Co}\right]$ vitamin $\mathrm{B}_{12}$ was administered by injection. A small decrease was observed in vitamin $B_{12}$-treated rats. The retention of injected [ ${ }^{58} \mathrm{Co}$ ] vitamin $\mathrm{B}_{12}$ by major organs of biotin-treated rats was lower than that of biotin-deficient rats. A lower content of $\left[{ }^{58} \mathrm{Co}\right.$ ] vitamin $\mathrm{B}_{12}$ was also detected in the organs, with the exception of the kidneys, of vitamin $\mathrm{B}_{12}$-treated rats. 4. These results are discussed in terms of an interrelationship between biotin and vitamin $\mathbf{B}_{12}$.
\end{abstract}

Interrelationships between biotin and vitamin $B_{12}$ have been observed by Marchetti \& Testoni (1964). The administration of vitamin $B_{12}$ to biotindeficient rats exerts a protective effect against biotin deficiency that results both in better growth and in a delay of deficiency symptoms. Moreover, vitamin $B_{12}$ supplementation may influence biotin-dependent enzymic activities, e.g. liver ornithine-carbamoyltransferase and aspartate-carbamoyltransferase activities.

In the present paper the effect of the administration of vitamin $\mathrm{B}_{12}$ on the absorption, excretion, retention and distribution among organs of $\left[{ }^{58} \mathrm{Co}\right]$ vitamin $B_{12}$ in biotin-deficient rats is reported. The results of comparative studies on the effect of supplementation with biotin are also given; previous studies have shown that biotin deficiency can induce changes in the metabolic pattern of vitamin $B_{12}$ in the rat (Puddu \& Marchetti, 1964).

\section{MATERIALS AND METHODS}

Treatment of animals. Weanling male rats of Wistar strain were divided into three groups. The first received a biotinfree diet (Marchetti, Pasquali \& Landi, 1965) of the following composition : vitamin-free casein, $20 \%$; sucrose, $59 \%$; salt mixture IV, 5\%; groundnut oil, $5 \%$; raw dried egg white, $11 \%$; vitamin supplements, $1 \%$. The second was given the same diet, but the raw dried egg white was replaced by egg white autoclaved at $120^{\circ}$ for $15 \mathrm{~min}$. and dried, and biotin
$(100 \mu \mathrm{g} . / \mathrm{kg}$.) was added. The third group received the biotin-free diet, supplemented with $100 \mu \mathrm{g}$. of vitamin $\mathrm{B}_{12} / \mathrm{kg}$. of diet.

All animals were given water ad libitum. The first group developed severe biotin deficiency after 60 days.

Determination of vitamin $B_{12}$ in liver. For the determination of vitamin $B_{12}$ in liver, six rats of each group were killed and the livers were removed immediately, homogenized and incubated with papain at $60^{\circ}$ for $1 \mathrm{hr}$. The total vitamin $B_{12}$ activity and the alkali-stable vitamin $B_{12}$ activity were estimated by the U.S. Pharmacopeia (1955) method, with Lactobacillus leichmannii A.T.C.C. 7830 as the test organism and ' $\mathrm{B}_{12}$ assay medium Difco' as the assay medium.

Measurement of $\left[{ }^{58} \mathrm{Co}\right] v i t a m i n B_{12} . \quad\left[{ }^{58} \mathrm{Co}\right]$ Vitamin $\mathrm{B}_{12}$ (obtained from The Radiochemical Centre, Amersham, Bucks.) with a specific activity of $1 \mu \mathrm{c} / \mu \mathrm{g}$. was either injected subcutaneously in $0.9 \% \mathrm{NaCl}$ solution or administered in aqueous solution by stomach tube. The amount of radioactivity used was $0 \cdot 2 \mu \mathrm{C}$ (representing only $200 \mathrm{~m} \mu \mathrm{g}$. of vitamin $\mathbf{B}_{12}$ ). After administration, the rats were placed individually in metabolism cages, and urine and faeces were collected separately for 4 days. The animals were then killed and the liver, kidneys, gastrointestinal tract (from the cardia to the end of the colon), heart and spleen were saved for radioactivity measurements. The tissues were dissolved in alkali, whereas the faeces were softened with $50 \%(v / v) \mathrm{H}_{2} \mathrm{SO}_{4}$. For all samples $4 \mathrm{ml}$. was counted, with standards of comparable geometry in a low-background $\gamma$ scintillation counter with a thallium-activated sodium iodide crystal installed in a well-type sample holder (Tracerlab model SC57/A). 
Table 1. Effect of the administration of biotin and vitamin $B_{12}$ on the vitamin $B_{12}$ content of the liver of the biotin-deficient rat

Experimental details are given in the text. The results are expressed as means \pm S.E.M., with the numbers of animals in parentheses.

\begin{tabular}{clrr} 
Group & \multicolumn{1}{c}{ Treatment } & $\begin{array}{r}\text { Wt. gain in } \\
60 \text { days }(\mathrm{g} .)\end{array}$ & $\begin{array}{r}\text { Liver vitamin } \mathrm{B}_{12} \\
(\mathrm{~m} \mu \mathrm{g} \cdot / \mathrm{g} \cdot \text { of tissue })\end{array}$ \\
1 & Biotin-deficient & $86 \pm 9 \cdot 7(18)$ & $81 \cdot 1 \pm 6 \cdot 5(6)$ \\
2 & Biotin-treated & $182 \pm 6 \cdot 1(18)$ & $47 \cdot 9 \pm 6 \cdot 2(6)$ \\
3 & Biotin-deficient vitamin B $_{12}$-treated & $157 \pm 9 \cdot 1(18)$ & $166 \cdot 9 \pm 8 \cdot 2(6)$
\end{tabular}

Table 2. Effect of the administration of biotin and vitamin $B_{12}$ on the absorption of orally fed $\left[{ }^{58} \mathrm{Co}\right]$ vitamin $B_{12}$ in the rat

Experimental details are given in the text. The absorption was calculated by subtracting faecal radioactivity from the oral dose $(200 \mathrm{~m} \mu \mathrm{g}$.). The results are expressed as means \pm S.E.M. of six determinations on different animals.

Radioactivity

(as $\mathrm{m} \mu \mathrm{g}$. of vitamin $\mathrm{B}_{12}$ )

\begin{tabular}{cl} 
Group & \multicolumn{1}{c}{ Treatment } \\
1 & Biotin-deficient \\
2 & Biotin-treated \\
3 & Biotin-deficient vitamin B $_{12}$-treated
\end{tabular}

Significance of results. The results were analysed statistically by Fisher's $t$ test, a difference between two mean values being regarded as significant when $P$ was no greater than 0.05 .

\section{RESULTS}

Liver biological activity of vitamin $B_{12}$. The results in Table 1 show a markedly higher weight gain in the vitamin $B_{12}$-treated rats (group 3) than that in the biotin-deficient rats (group 1$)(P<0.001)$, although slightly lower than that in the animals given biotin (group 2). Moreover, the vitamin $\mathbf{B}_{12}$ content of the liver of rats receiving a biotin-free diet is higher $(P<0.05)$ than that of biotin-treated rats, but lower than that of vitamin $B_{12}$-treated rats $(P<0.001)$.

Absorption and organ uptake of orally administered [ ${ }^{58} \mathrm{Co}$ ]vitamin $B_{12}$. Table 2 shows that no significant variation in the absorption of orally administered [ ${ }^{58} \mathrm{Co}$ ]vitamin $\mathrm{B}_{12}$ was observed between biotindeficient rats and those receiving biotin. The absorption by biotin-deficient vitamin $\mathrm{B}_{12}$-supplemented rats was not significantly lower than that of biotin-deficient animals.

The uptake of orally given [ ${ }^{58} \mathrm{Co}$ ] vitamin $\mathrm{B}_{12}$ by various organs is shown in Table 3 . No difference in the organ uptake was observed between biotindeficient and biotin-supplemented rats if the results were expressed on the basis of the weight of the whole organ. On the other hand, if the results were expressed per unit weight of organ, a significant decrease of vitamin $B_{12}$ uptake was observed in the liver $(P<0.02)$ and kidneys $(P<0.02)$ of biotintreated rats as compared with biotin-deficient rats.

In rats given the biotin-deficient vitamin $B_{12}$ supplemented diet the [ ${ }^{58} \mathrm{Co}$ ] vitamin $\mathrm{B}_{12}$ content of the kidneys showed an increase as compared with biotin-deficient rats, whether expressed per unit weight of the organ or on the basis of the weight of the whole organ $(P<0.02)$.

In contrast with the kidneys, radioactivity taken up by the spleen and the heart was less in vitamin $B_{12}$-supplemented rats $(P<0.01$ and $P<0.05$ respectively), whereas no difference between the two groups was apparent in the liver and gastrointestinal tract if the results were expressed either per unit weight of the organ or per whole organ.

Excretion and retention of injected $\left[{ }^{58} \mathrm{Co}\right]$ vitamin $B_{12}$. No significant differences were observed in radioactivity in the urine and faeces between biotindeficient and biotin-treated rats. A small decrease of [ ${ }^{58} \mathrm{Co}$ ] vitamin $\mathrm{B}_{12}$ excretion was noted in rats receiving the biotin-deficient diet supplemented with vitamin $\mathbf{B}_{12}$ as compared with biotin-deficient rats $(P<0.01)$ (Table 4$)$. The retention of [ $\left.{ }^{58} \mathrm{Co}\right]-$ vitamin $B_{12}$ by the organs (liver, $P<0.001$; kidneys, $P<0.001$; gastrointestinal tract, $P<0.01$; spleen, $P<0.001$; heart, $P<0.02$ ) of biotin-treated rats, whether expressed per unit weight of the organ or per whole organ, was lower than that of biotindeficient animals. The liver $(P<0.001)$, gastro- 
intestinal tract $(P<0.001)$, spleen $(P<0.01)$ and heart $(P<0.01)$ of biotin-deficient vitamin $\mathrm{B}_{12}$ treated rats retained less radioactivity as compared with biotin-deficient rats, whereas the kidneys accumulated more $\left[{ }^{58} \mathrm{Co}\right.$ ]vitamin $\mathrm{B}_{12}$ (Table 3), whether the results were expressed either per unit weight of the organ or per whole organ $(P<0.001)$.

\section{DISCUSSION}

The administration either of vitamin $B_{12}$ or of biotin to biotin-deficient rats results in significant changes in the metabolism of [ ${ }^{58} \mathrm{Co}$ ] vitamin $\mathbf{B}_{12}$, administered either orally or subcutaneously. These results could be interpreted as demonstrating further interrelationships between biotin and vitamin B $_{12}$.

Biotin-deficient vitamin $B_{12}$-treated rats retained less [ ${ }^{58} \mathrm{Co}$ ]vitamin $\mathrm{B}_{12}$ in some organs studied, but the renal uptake was greater than that in biotindeficient rats. The decreased uptake of radioactivity by the organs of vitamin $\mathrm{B}_{12}$-treated rats may be due in part to isotope dilution and to flushing. On the other hand, the increased retention of [ $\left.{ }^{58} \mathrm{Co}\right]$ vitamin $\mathrm{B}_{12}$ by the kidney may be related to the role played by this organ in the storage and turnover of vitamin $\mathrm{B}_{12}$, as postulated by Harte, Chow $\&$ Barrows (1953). In fact, it has been demonstrated (Okuda, 1962) that, unlike other organs, the kidney has a large capacity for storing vitamin $B_{12}$ absorbed in excess of the immediate need and that it releases it later. Such accumulation and release do not occur in rats that have not received vitamin $B_{12}$ in sufficient amounts. The changes in the metabolic pattern of vitamin $B_{12}$ observed in biotin-deficient rats as compared with those supplemented with vitamin $\mathrm{B}_{12}$ are similar to the changes observed in rats maintained on vitamin $B_{12}$-free diets as compared with rats that have been supplied with the vitamin (Sauberlich, 1959; Okuda, 1962).

Since it has been demonstrated that the biotindeficient diet cannot be considered a diet deficient both in vitamin $\mathbf{B}_{12}$ and biotin (Marchetti \& Testoni, 1964), then, as a result of the experiments presented above, it seems that biotin deficiency may also induce a conditioned deficiency of vitamin $B_{12}$, e.g. an impaired utilization of this vitamin. Other studies on the relationships between biotin and vitamin $B_{12}$ (Marchetti \& Testoni, 1964; Puddu \& Marchetti, 1964) agree with this hypothesis. In fact, it was found that the biotin-deficient rats have a high microbiological activity of vitamin $B_{12}$ in the liver and yet require more vitamin $B_{12}$; this is suggested by the favourable effect on the growth rate and deficiency symptoms exerted by the administration of a large quantity of vitamin $\mathbf{B}_{12}$ and also by the higher retention of [ ${ }^{58} \mathrm{Co}$ ] vitamin $\mathrm{B}_{12}$ in the storage organs of biotin-deficient rats. 
Table 4. Effect of the administration of biotin and vitamin $B_{12}$ on the excretion of injected $\left[{ }^{58} C o\right] v i t a m i n ~ B_{12}$ in the biotin-deficient rat

Experimental details are given in the text. The results are expressed as the means \pm S.E.M. of six determinations on different animals.

Radioactivity

(as $\mathrm{m} \mu \mathrm{g}$. of vitamin $\mathrm{B}_{12}$ )

\begin{tabular}{cl} 
Group & \multicolumn{1}{c}{ Treatment } \\
1 & Biotin-deficient \\
2 & Biotin-treated \\
3 & Biotin-deficient vitamin B $_{12}$-treated
\end{tabular}

\section{REFERENCES}

Harte, R. A., Chow, B. F. \& Barrows, L. (1953). J. Nutr. $49,669$.

Marchetti, M., Pasquali, P. \& Landi, L. (1965). Biochem.J. 94, 763.
Marchetti, M. \& Testoni, S. (1964). J. Nutr. 84, 249. Okuda, K. (1962). J. Nutr. 77, 131.

Puddu, P. \& Marchetti, M. (1964). J. Nutr. 84, 255.

Sauberlich, H. E. (1959). J. Nutr. 69, 309.

U.S. Pharmacopeia, 15th rev. ed. (1955). Easton, Pa.: Mack Publishing Co. 